\title{
Isolated Dural and Calvarial Metastasis in a patient with Breast Carcinoma: a Case Report
}

\section{Meme Kanserli Hastada İzole Dural-Kalvaryal Metastaz: Olgu Sunumu}

\author{
Bülent Kaya, Fatih Erdi, Fatih Keskin, Yaşar Karataş, Emir Kaan İzci, Gökhan Toğuşlu \\ Necmettin Erbakan Üniversitesi, Meram Tıp Fakültesi, Nöroşirurji Ana Bilim Dalı, Konya
}

Dergiye Ulaşma Tarihi:10/12/2014 Dergiye Kabul Tarihi:24/02/2015 Doi: : 10.5505/aot.2015.18291

\section{ÖZET:}

Literatürde malign neoplazmların dural metastazları ile ilgili az bilgi bulunmaktadır. Kesin etyopatogenezleri ve tedavi stratejileri tartışmalıdır. Dura matere en sık metastaz meme kanserinden olmaktadır. 41 yaşında bayan hasta kliniğimize baş ağrısı ve sol parietalde şişlik şikayeti ile başvurdu. Hasta 3 yıl önce infiltratif duktal kanser nedeni ile opere edilmişti. Sol kalvaryal ve dura metastazı tespit edildi ve sol pariyetal kraniotomi ile cerrahi rezeksiyon uyguland. Hasta operasyondan sonra tüm beyin radyoterapi aldı. Bu yazıda kafatası ve duraya metastaz yapan bir kanser vakasını ve bu nadir hastalığın ana özelliklerini tartıştık.

Anahtar Kelimeler: Dura, Metastaz, Kalvaryum, Meme, Kanser

\begin{abstract}
There is little information about the dural metastasis of malign neoplasms in the literature. The exact etiopathogenesis and treatment strategies are controversial. The most common site for breast cancer metastasis is dura matter. Forty one years old female patient admitted to our clinic with headache and left parietal swelling complaints. The patient was operated due to infiltrative ductal cancer three years ago. A left parietal calvarial and dural metastasis determined and surgically resected via left parietal craniotomy. The patient underwent whole brain radiotherapy after this operation. In this report we present an unusual case of cancer metastasis to the skull and dura and discuss the main features of this disease.
\end{abstract}

Key words: Dura, Metastasis, Calvarium, Breast, Cancer

\section{Giriş}

İntrakranial metastazlar en sik beyin parankimine olmakla beraber leptomeningeal ve dural bölgeye de olabilirler. İlerlemiş sistemik kanserli hastaların otopsilerinde $\% 9$ oranında intrakranial dural metastaz bildirilmiştir. Yine otopsi serilerinde sistemik malign neoplazmlara bağlı intrakranial metastaz oran $1 \% 24$ olarak bildirilmektedir $(1,2,3)$.

Dural metastazları da içeren intrakranial metastazlar, sistemik kanserli hastalarda morbidite ve mortaliteye neden olan en önemli sebeplerden biridir (1).

Dural metastazlar fokal nöbet, afazi, görme alanı defekti, hemiparezi gibi fokal bulgularla ortaya çıkabileceği gibi, baş ağrısı, konfüzyon, hafiza kayb1, letarji ve kusma gibi sistemik bulgulara da neden olabilir (2). Literatürde kronik subdural hematom gibi atipik bulgulara neden olan dural metastazlar da bildirilmiştir (3).
Biz burada sol pariyetal bölgede şişlik ve ağrı ile başvuran bir olguyu sunuyoruz.

\section{Olgu Sunumu}

41 yaşında bayan hasta şiddetli baş ağrısı ve kafasında şişlik nedeni ile polikliniğimize başvurdu. Hastanın tıbbi geçmişinden 2011 yılında meme kanseri tanısı ile opere edildiği öğrenildi. Hastanın histopatolojik tanısı grade 2 infiltratif duktal karsinom olarak gelmiş. İmmünohistokimyasal incelemede östrojen $\% 80(+++)$, progesteron \%80 (+++), CERB B2 $(++)$, E-Cadherin $(+)$ ekspresyonu saptanmış. Tümör T2N1M0 olarak evrelendirilmiş. Hasta neoadjuvan olarak 4 kür Adriamisin + Siklofosfamid ve 4 kür de Dosetaksel almış. Daha sonra opere edilerek sol radikal mastektomi uygulanmış. Takiben sol gögüs duvarı lenfatiklere 25 fraksiyonda 50 Gy küratif radyoterapi uygulanmıs. Hastanın altı ay önce şiddetli baş ağrıları başlamış. Ağrıları analjezik ile geçiyormuş. Son 1 aydır başında 
şişlik oluşmuş ve giderek büyümüş. Fizik muayenesinde sol pariyetal bölgede yaklaşık $3 \times 3 \mathrm{~cm}$ lik dokunulabilen ağrısız kitle mevcuttu. Nörolojik muayenesi normal idi. Tanısal amaçlı yapılan beyin manyetik rezonans görüntülemede (MRG) lezyon seviyesinde durada yaklaşı $1 \mathrm{~cm}$ 'ye yakın kalınlaşma ve belirgin kontrast tutulumu vardı. Ayrıca dura, kemik ve saçlı deriyi tutan metastatik yumuşak doku kitlesi görüldü (Resim 1).

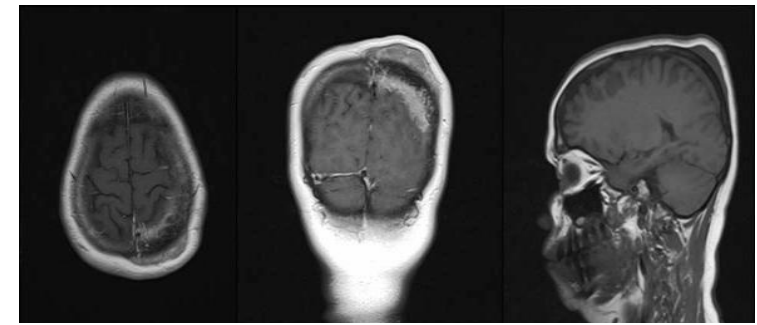

Resim 1: Olgunun ameliyat öncesi çekilen kontrastlı aksiyel ve koronal, kontrastsız sagital T1ağırlıklı manyetik rezonans görüntüleme kesitleri.

Hasta operasyona alınd. Duraya invaze kitle ve tümörle infiltratif kafatası bölgesi gross total olarak eksize edildi (Resim 2).

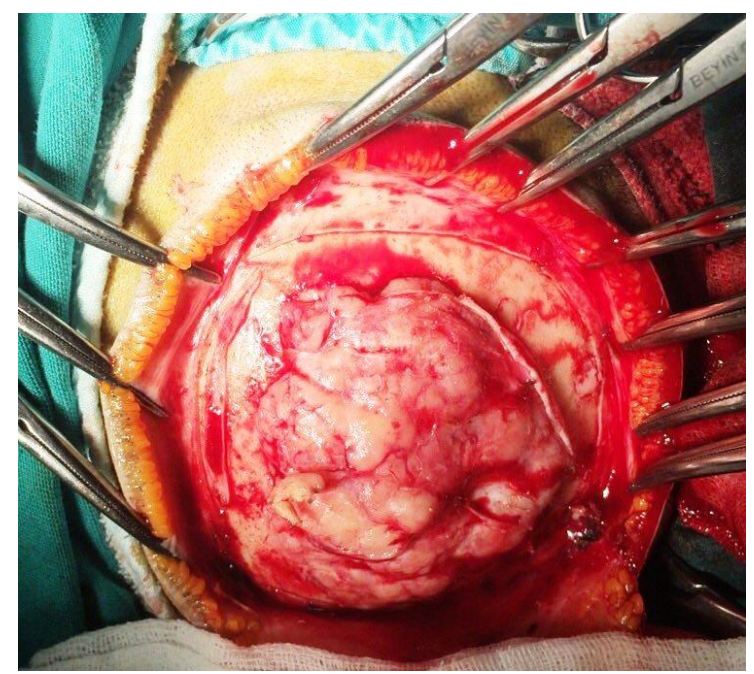

Resim 2: Tümörün intraoperatif görüntüsü.

Patolojik değerlendirme sonucunda infiltratif duktal karsinom metastazı olarak değerlendirildi. Kranioplasti uygulanmadi. Tüm vücut F-18 FDG PET/BT'sinde başka metastaz tespit edilmedi. Hastaya toplam 10 fraksiyonda 30 Gy tüm beyin palyatif RT uygulandi.

\section{Tartışma}

Dural metastazlar üzerinde çok çalışma yapılmamış bir konudur. Klinik prezantasyonlarının farklılık göstermesi ve klasik radyolojik bir tanımlaması olmaması nedeni ile tan1 konulmasi zorluklar içermektedir. Ayırıcı tanısında menegiomlar, gliomlar, hipofiz adenomları, akustik nörinom gibi primer beyin tümörleri, serebral emboli, serebral tromboz gibi vasküler hastalıklar ve enfeksiyonlar say1labilir (4).

Literatürde dural metastaza en s1k sebep olan kanserlerin sirası ile meme kanseri, prostat kanseri ve akciğer kanseri olduğu bildirilmiştir. İlerlemiş sistemik kanserli hastaların otopsilerinde $\% 9$ oranında intrakranial dural metastaz bildirilmiştir $(1,2,4)$. Bizim olgumuzda da bulunan infiltratif duktal karsinom en sik dural metastaza neden olan meme kanseri tipidir. Lobuler karsinomda dural metastaza neden olabilir $(2,5)$.

Dural metastazların etyolojisinde primer tümöre bağlı olarak 2 tip gelişim mekanizması olduğu düşünülmektedir. Bunlardan birincisi meme ve prostat kanserinde olduğu gibi kafatası kemiklerine olan direkt metastazların duraya uzanımı ve ikinci olarak akciğer kanserinde olduğu gibi lenf yolu ile yayılım olabilir (6). Dural metastazların en sik hematojen yolla olduğunu ileri süren çalışmalarda mevcuttur (7). Olgumuzda başka organ tutulumu olmamas1 ve primer kanser odağının meme olması nedeni ile metastazın kafatası kemiğinden direk invazyon yolu ile olduğu düşünülmektedir. Ayrıca meme kanserinin başkaca metastaz bölgesi olmadan ilk olarak kraniyal kemik ve dural metastaz ile kendini göstermesi açısından ilginç bir olgudur. Beyin parankim metastazı s1k görülebilirse de izole kalvaryal kemik metastazı ve dura invazyonu nadirdir $(1,2,4)$.

Dural metastazlı hastalarda çok farklı klinik bulgular ortaya çıkabilmektedir. Dural metastazlar fokal nöbet, afazi, görme alanı defekti, hemiparezi gibi fokal bulgularla ortaya çıkabileceği gibi, baş ağrısı, konfüzyon, hafiza kayb1, letarji ve kusma gibi sistemik bulgularla da ortaya çıkabilir (2).

Olgumuzda baş ağrısı ve başındaki şişlik dışında bir bulgu yoktu. Nörolojik muayenesi intakt1. Dural metastaz tanısı tomografi, MRG, MRG spektroskopi gibi gelişen görüntüleme 
yöntemleri ile kolaylaşmıştır $(1,8,10)$. $\mathrm{Bu}$ nedenle bu olgulara günümüzde daha çabuk tanı konulabilmektedir.

Dural metastazlara yaklaşımlar primer kanser tipine göre değişmektedir. Tedavi yöntemi standardize edilmemiştir. Ancak tedavi yöntemleri arasında cerrahi tedavinin yanı sıra tek başına radyoterapi, tek başına kemoterapi, radyo-kemo terapi kombinasyonu veya sadece destek tedavisi sayılabilir (1).

Dural metastazlara yaklaşımda metastaz sayıs1 ve lezyon bölgesinin cerrahiye uygunluğu da cerrahi planlamasında önemli kriterlerdir (6). Olgumuzda metastaz odağının tek olması ve cerrahi olarak ulaşılabilir bir bölgede olması nedeni ile cerrahi uygulanmıştır. Kitlenin kemiğe ve duraya invaze olduğu görülmüş ve kemik, duraya invaze olan tümör totale yakın eksize edilmiştir.

Sonuç olarak özellikle meme kanserli hastalarda dural metastazlar gelişebilmektedir. Meme kanserli hastaların takibinde nörolojik belirti olması halinde dural metastaz tanis1 akılda tutulmalıdır. $\mathrm{Bu}$ metastazlarla ilgili yapılacak geniş çaplı çalışmalar tedavi yaklaşımlarında gelişmeler sağlayacaktır.

\section{Çıkar Çatışması: Yok Kaynaklar}

1. NayakL, Abrey LE, Iwamoto FM. Intracranial Dural Metastases.Cancer 2009;115(9):1947-53

2. Higashi H, Fukutomi T, Watanabe T, Adachi I, Narabayashi, M, Shibui S, et al. Seven cases of breast cancer recurrence limited to the central nervous system without other visceral metastases. Breast Cancer 2000;7(2):153-56

3. Tseng SH, Liao CC, Lin SM, Chen Y, Shun CT. Dural metastasis in patients with malignant neoplasm and chronic subdural hematoma. Acta Neurol Scand 2003;108(1):43-6

4. Maroldi R, Ambrosi C, FarinaD. Metastatic disease of the brain: Extra-axial metastases (skull, dura, leptomeningeal) and tumour spread. European Radiology 2005;15(3):617-26

5. Tham Y. L, Sexton K, KramerR, Hilsenbeck S, Elledge R. Primary breast cancer phenotypes associated with propensity for central nervous system metastases. Cancer 2006;107(4): 696-704

6. Agarwal B,Das P, Nasim M. Dural Metastatic Cancer From Primary Breast Carcinoma.Int J Neurosci. 2010;120(6):442-6

7. Kleinschmidt-DeMasters BK. Dural metastases. A retrospective surgical and autopsy series. Archives of Pathology and Laboratory Medicine 2001;125(7):880-887

8. Bendszus M, Warmuth-Metz M, Burger R, Klein R, Tonn JC, Solymosi L. Diagnosing dural metastases: The value of $1 \mathrm{H}$ magnetic resonance spectroscopy. Neuroradiology 2001;43(4):285-89

9. Sijens PE, Oudkerk M, Bendszus M, Warmuth-Metz M, Burger R, Klein R, et al. Diagnosing dural metastases. Neuroradiology 2002;44(3): 275 